\title{
APPLICATION OF LIAPUNOV THEORY TO BOUNDARY VALUE PROBLEMS ${ }^{1}$
}

\begin{abstract}
J. H. GEORGE AND W. G. SUTTON
ABSTRACT. The theory of Liapunov's direct method is developed for boundary value problems occurring in ordinary differential equations. Conditions are given in terms of a Liapunov function which are sufficient to insure uniqueness and existence of solutions of boundary value problems. A suitable Liapunov function is obtained to give conditions obtained by Hartman as special cases.
\end{abstract}

1. Introduction. Many techniques and theories developed for boundary value problems of ordinary differential equations originated as initial value concepts. For example, fixed point theorems [1], Picard's iteration [4], and differential inequalities [2], [3], [4] are commonly used techniques in both initial and boundary value problems.

A theoretical technique that has proved extremely useful in initial value theory [5], but does not seem to be given its due in boundary value theory, is the direct method of Liapunov. In initial value problems, since necessary and sufficient Liapunov function conditions are obtained for many types of solution behavior, the theory can be considered as a unifying concept. That is, all known sufficient conditions can be obtained by choosing the proper Liapunov function, as is done by Yoshizawa [5, p. 10] for the Lipschitz condition as a uniqueness criterion. (See George [7] for a Liapunov function for more general uniqueness theorems.) Yoshizawa [3] has obtained a Liapunov result for boundary value problems, giving necessary and sufficient conditions for the boundary value solution to remain between two estimates obtained by differential inequalities.

We shall develop a Liapunov theory for existence and uniqueness of solutions of boundary value problems. Also the existing theory of Hartman will be shown to be included in our theory by a suitable Liapunov function selection.

2. Preliminaries and notation. Let us consider the system of ordinary differential equations

\footnotetext{
Presented to the Society, January 23, 1970; received by the editors September 29, 1969.

AMS Subject Classifications. Primary 3436, 3404, 3451.

Key Words and Phrases. Liapunov stability theory, boundary value problems, existence and uniqueness.

1 This research was supported in part by NASA Grant NAS8-21434.
} 


$$
x^{\prime \prime}=f\left(t, x, x^{\prime}\right),
$$

where $x$ and $f$ are $n$-vectors, ${ }^{\prime}=d / d t$, and $f$ is a function defined and continuous on a domain $D=[a, b] \times \bar{D}$, where $[a, b]$ is an interval on the real line and $\bar{D} \subset R^{2 n}$.

$x(t)$ belongs to class $C^{2}\left[t_{1}, t_{2}\right]$ if $x^{\prime \prime}(t)$ is continuous on $\left[t_{1}, t_{2}\right]$.

The boundary value problem is that of finding a solution $x(t)$ of (1) on $[a, b]$ satisfying for $b>a$,

$$
x(a)=A, \quad x(b)=B .
$$

The corresponding initial value problem is obtaining a solution $x(t)$ of (1) satisfying the initial values

$$
x(a)=A, \quad x^{\prime}(a)=\alpha .
$$

A Liapunov function $V\left(t, x, x^{\prime}\right)$ is a continuous, locally Lipschitzian with respect to $\left(x, x^{\prime}\right)$, real valued function. Corresponding to $V\left(t, x, x^{\prime}\right)$ define

$$
\begin{gathered}
V_{f}^{\prime}\left(t, x, x^{\prime}\right)=\liminf _{h \rightarrow 0^{+}} h^{-1}\left[V\left(t+h, x+h x^{\prime}, x^{\prime}+h f\left(t, x, x^{\prime}\right)\right)-V\left(t, x, x^{\prime}\right)\right], \\
V^{\prime}\left(t, x, x^{\prime}\right)=\liminf _{h \rightarrow 0^{+}} h^{-1}\left[V\left(t+h, x(t+h), x^{\prime}(t+h)\right)-V\left(t, x(t), x^{\prime}(t)\right)\right] .
\end{gathered}
$$

Lemma 2.1 (Yoshizawa [5, p. 4]). If $V\left(t, x, x^{\prime}\right)$ is a Liapunov function and $x(t)$ is a solution of (1), then $V^{\prime}\left(t, x(t), x^{\prime}(t)\right)=V_{f}^{\prime}\left(t, x(t), x^{\prime}(t)\right)$ and $V\left(t, x(t), x^{\prime}(t)\right)$ is nonincreasing (nondecreasing) if and only if $V_{f}^{\prime}\left(t, x, x^{\prime}\right) \leqq 0\left(V_{f}^{\prime}\left(t, x, x^{\prime}\right) \geqq 0\right)$.

LEMMA 2.2. Let $x(t)$ be a solution of (1) satisfying

$$
x(a)=0, \quad x^{\prime}(a)=0,
$$

and suppose that either $x(t) \not \equiv 0$ or $x^{\prime}(t) \not \equiv 0$ on $[a, b]$. Then there exists an open interval $I \subset[a, b]$ such that both $x(t) \neq 0$ and $x^{\prime}(t) \neq 0$ on $I$.

Proof. Suppose $x(t) \neq 0$ on $[a, b]$. Then by continuity of $x(t)$ there exists an open interval $I_{1}=\left(t_{0}, t_{1}\right)$ such that $x(t) \neq 0$ on $I_{1}$, and $x\left(t_{0}\right)=0$. Assume $x^{\prime}(t) \equiv 0$ on $I_{1}$. Then $x(t) \equiv c$ on $I_{1}$, where $c$ is a constant, and $c=0$ since $x\left(t_{0}\right)=0$. Since $x^{\prime}(t)$ is continuous there exists an open interval $I_{2} \subset I_{1}$ where $x^{\prime}(t) \neq 0$. Thus on $I=I_{1} \cap I_{2}, x(t) \neq 0$ and $x^{\prime}(t) \neq 0$. If $x^{\prime}(t) \neq 0$ on $[a, b]$ a similar argument concludes the proof.

Let $\langle x, y\rangle$ be the inner product in $n$-dimensional Euclidean space and let $\|x\|^{2}=\langle x, x\rangle$ be the corresponding norm.

3. Uniqueness and continuability. Let $u(t)$ be a solution of the boundary value problem (1) and (2). What conditions on $f$ insure 
that $u(t)$ is the only solution of (1) and (2)? Many criteria on $f$ are given to insure uniqueness; for example, the Lipschitz condition [4] and nondecreasing properties [2, p. 317] are standard sufficient conditions. We shall develop a Liapunov theory for boundary value problems which gives sufficient conditions for uniqueness.

Suppose $v(t)$ is another solution of (1) and (2). If $x=u-v$, then $x$ must satisfy

$$
\begin{gathered}
x^{\prime \prime}=f\left(t, u, u^{\prime}\right)-f\left(t, u-x, u^{\prime}-x^{\prime}\right)=F\left(t, x, x^{\prime}\right), \\
x(a)=0, \quad x(b)=0 .
\end{gathered}
$$

Now $F(t, 0,0) \equiv 0$ and hence $x(t) \equiv 0$ is a solution satisfying (5) and (6). We have proved the following:

LeMma 3.1. $x(t) \equiv 0$ is the only solution of (5) and (6) if and only if $u(t)$ is the only solution of (1) and (2).

Theorem 3.1. For $F$ defined in (5), if there exists a Liapunov function $V\left(t, x, x^{\prime}\right)$ defined on $D$ such that

(i) $V\left(t, x, x^{\prime}\right)=0$ if $x=0$,

(ii) $V\left(t, x, x^{\prime}\right)>0$ if $x \neq 0$,

(iii) $V_{F}^{\prime}\left(t, x, x^{\prime}\right) \geqq 0$ in the interior of $D$,

then there is at most one solution of (1) and (2).

Proof. By Lemma 3.1 it suffices to show $x(t) \equiv 0$ is the unique solution of (5) and (6). Suppose there exists a solution $\phi(t)$ of (5) such that $\phi(a)=0, \phi(b)=0$, and $\phi\left(t_{1}\right) \neq 0$ for some $t_{1} \in(a, b)$. Then there exists $\left[t_{2}, t_{3}\right] \subset[a, b]$ such that $t_{1} \in\left(t_{2}, t_{3}\right), \phi\left(t_{2}\right)=\phi\left(t_{3}\right)=0$, and $\phi(t) \neq 0$ on $\left(t_{2}, t_{3}\right)$. Thus $V\left(t, \phi(t), \phi^{\prime}(t)\right)>0$ on $\left(t_{2}, t_{3}\right)$. Since $V_{F}^{\prime}\left(t, x, x^{\prime}\right)$ $\geqq 0, V\left(t, \phi(t), \phi^{\prime}(t)\right)$ is nondecreasing along the solution $\phi(t)$ and thus $V\left(t_{3}, \phi\left(t_{3}\right), \phi^{\prime}\left(t_{3}\right)\right)>0$, a contradiction.

Corollary 3.1. If there exists a Liapunov function as in Theorem 3.1 except that (ii) holds when both $x$ and $x^{\prime}$ are $\neq 0$, then a solution of (1) and (2) is unique.

Proof. Follows as in Theorem 3.1 by using Lemma 2.2.

EXAMPLE. In Hartman [1, p. 427] the condition $\langle x, F\rangle+\left\|x^{\prime}\right\|^{2}>0$ if $x \neq 0$ and $\left\langle x, x^{\prime}\right\rangle=0$ is given to insure uniqueness of $x \equiv 0$. By choosing $V\left(t, x, x^{\prime}\right)=\langle x, x\rangle$ all conditions of Theorem 3.1 are satisfied, since Hartman's condition insures $V$ does not have a maximum, and hence $V_{F}^{\prime}\left(t, x, x^{\prime}\right) \geqq 0$.

Because it may be convenient to give continuability conditions, such as are required by Jackson [2] in the theory of sub and superfunctions, as Liapunov conditions, it will simply be mentioned that 
the necessary and sufficient conditions for continuability are given by Yoshizawa [5, pp. 11-17].

4. Existence. If $f$ is bounded, then it is possible to give local existence results such as the following (see also [1, p. 424]):

Theorem 4.1 (Jackson [2, p. 309]). Let $M>0$ and $N>0$ be given real numbers and let $q=\max \left\|f\left(t, x, x^{\prime}\right)\right\|$ on $[a, b] \times\{x:\|x\| \leqq 2 M\}$ $\times\left\{x^{\prime}:\left\|x^{\prime}\right\| \leqq 2 N\right\}$.

Let $\delta=\min \left[(8 M / q)^{1 / 2},(2 N / q)\right]$. Then for any $\left[t_{1}, t_{2}\right] \subset[a, b]$ such that $0<t_{2}-t_{1} \leqq \delta$,

$$
x\left(t_{1}\right)=x_{1}, \quad x\left(t_{2}\right)=x_{2}, \text { where }\left\|x_{1}\right\| \leqq M, \quad\left\|x_{2}\right\| \leqq M,
$$

and where $\left\|\left(x_{2}-x_{1}\right) /\left(t_{2}-t_{1}\right)\right\| \leqq N$, the boundary value problem (1) and (7) has at least one solution.

Lemma 4.1 (Hartman [1, p. 432]). Suppose $f\left(t, x, x^{\prime}\right)$ is defined and continuous on $D_{M}=[a, b] \times\{x:\|x\| \leqq M\} \times R^{n}$ and let $N>0$ be given. Then for any $\left[t_{1}, t_{2}\right] \subset[a, b]$ there exists a continuous bounded function $g\left(t, x, x^{\prime}\right)$ defined on $\left[t_{1}, t_{2}\right] \times R^{2 n}$ such that $f\left(t, x, x^{\prime}\right)=g\left(t, x, x^{\prime}\right)$ on $D_{1}=\left[t_{1}, t_{2}\right] \times\{x:\|x\| \leqq M\} \times\left\{x^{\prime}:\left\|x^{\prime}\right\| \leqq N\right\}$.

We are now in a position to give Liapunov sufficient conditions for the existence of a solution of the boundary value problem (1) and (7). For $g\left(t, x, x^{\prime}\right)$ obtained in Lemma 4.1, consider

$$
x^{\prime \prime}=g\left(t, x, x^{\prime}\right) \text {. }
$$

THEOREM 4.2. Let $x(t)$ be a solution of (8) defined on $\left[t_{1}, t_{2}\right] \subset[a, b]$ and suppose that $\left\|x\left(t_{1}\right)\right\| \leqq M,\left\|x\left(t_{2}\right)\right\| \leqq M$. Suppose there exists $a$ Liapunov function $V\left(t, x, x^{\prime}\right)$ defined on $D_{2}=\left[t_{1}, t_{2}\right] \times\{x:\|x\| \geqq M\}$ $\times R^{n}$ such that

(i) $V\left(t, x, x^{\prime}\right)=0$ whenever $\|x\|=M$,

(ii) $V\left(t, x, x^{\prime}\right)>0$ whenever $\|x\|>M$,

(iii) $V_{o}^{\prime}\left(t, x, x^{\prime}\right) \geqq 0$ in the interior of $D_{2}$.

Then $\|x(t)\| \leqq M$ on $\left[t_{1}, t_{2}\right]$.

Proof. Follows as in Theorem 3.1.

EXAMPLE. Hartman $[1$, p. 433] gives the following condition to insure $\|x(t)\| \leqq M$.

$$
\langle x, g\rangle+\left\|x^{\prime}\right\|^{2}>0 \quad \text { if }\left\langle x, x^{\prime}\right\rangle=0 \text { and }\|x\| \geqq M .
$$

If $V\left(t, x, x^{\prime}\right)=\langle x, x\rangle-M^{2}$, then Hartman's condition implies $V$ evaluated along a solution $x(t)$ of (8) does not have a maximum at 
any point $t \in\left[t_{1}, t_{2}\right]$ where $\|x(t)\| \geqq M$. Hence this $V$ satisfies all conditions of Theorem 4.2, thus insuring $\|x(t)\| \leqq M$ on $\left[t_{1}, t_{2}\right]$.

THEOREM 4.3. Let $x(t)$ be any function of class $C^{2}\left[t_{1}, t_{2}\right]$ satisfying $\|x(t)\| \leqq M$ on $\left[t_{1}, t_{2}\right]$. Suppose there exists a Liapunov function $V\left(t, x, x^{\prime}\right)$ defined on $D_{3}=\left[t_{1}, t_{2}\right] \times\{x:\|x\| \leqq M\} \times R^{n}$ satisfying

(i) $V\left(t_{1}, x\left(t_{1}\right), x^{\prime}\left(t_{1}\right)\right)=0$,

(ii) $V\left(t, x, x^{\prime}\right) \geqq\left(t-t_{1}\right) \phi\left(\left\|x^{\prime}\right\|\right)$, where $\phi$ is a positive continuous function defined on $[0, \infty)$ such that $\phi(r) \rightarrow \infty$ as $r \rightarrow \infty$,

(iii) there exists a positive constant $L$ such that $V^{\prime}\left(t, x, x^{\prime}\right) \leqq L$ in the interior of $D_{3}$.

Then there exists a positive constant $N$ such that $\left\|x^{\prime}(t)\right\| \leqq N$ on $\left[t_{1}, t_{2}\right]$.

Proof. By (ii) there exists a constant $N$ such that $\phi(r)>L$ whenever $r \geqq N$, and by (iii),

$$
V\left(t, x(t), x^{\prime}(t)\right)-V\left(t_{1}, x\left(t_{1}\right), x^{\prime}\left(t_{1}\right)\right) \leqq L\left(t-t_{1}\right) \quad \text { for any } t \in\left[t_{1}, t_{2}\right] .
$$

Suppose that $\left\|x^{\prime}\left(t_{3}\right)\right\| \geqq N$ for some $t_{3} \in\left(t_{1}, t_{2}\right]$. Then

$$
\begin{aligned}
0=V\left(t_{1}, x\left(t_{1}\right), x^{\prime}\left(t_{1}\right)\right) & \geqq V\left(t_{3}, x\left(t_{3}\right), x^{\prime}\left(t_{3}\right)\right)-L\left(t_{3}-t_{1}\right) \\
& \geqq\left(t_{3}-t_{1}\right)\left(\phi\left(\left\|x^{\prime}\left(t_{3}\right)\right\|\right)-L\right) \\
& >0, \quad \text { a contradiction. }
\end{aligned}
$$

Hence $\left\|x^{\prime}(t)\right\|<N$ on $\left(t_{1}, t_{2}\right]$, and since $x^{\prime}(t)$ is continuous on $\left[t_{1}, t_{2}\right]$, $\left\|x^{\prime}(t)\right\| \leqq N$ on $\left[t_{1}, t_{2}\right]$.

Theorem 4.4. Suppose $f\left(t, x, x^{\prime}\right)$ is defined and continuous on $D_{M}$ and suppose there exist two Liapunov functions with the properties given in Theorems 4.2 and 4.3 respectively. Then the boundary value problem (1) and (7) has at least one solution.

Proof. For the constant $N$ given by Theorem 4.3 construct the function $g\left(t, x, x^{\prime}\right)$ given by Lemma 4.1. Since the function $g\left(t, x, x^{\prime}\right)$ is continuous and bounded on $\left[t_{1}, t_{2}\right] \times R^{2 n}$, the boundary value problem (8) and (7) has a solution $x(t)$. Since $\left\|x\left(t_{1}\right)\right\| \leqq M$ and $\left\|x\left(t_{2}\right)\right\| \leqq M$, Theorem 4.2 implies $\|x(t)\| \leqq M$ on $\left[t_{1}, t_{2}\right]$. Then Theorem 4.3 gives $\left\|x^{\prime}(t)\right\| \leqq N$ on $\left[t_{1}, t_{2}\right]$, and since $f\left(t, x, x^{\prime}\right)=g\left(t, x, x^{\prime}\right)$ on $D_{1}, x(t)$ is a solution of the boundary value problem (1) and (7).

5. Obtaining existence from uniqueness. This interesting concept was introduced by Lasota and Opial [6] and Jackson [2]. We shall restrict our considerations in this section to second order differential equations where $f(t, x, y)$ is defined, continuous and real valued on the strip $D_{4}=(a, b) \times R^{2}$. Let $D_{5}=\left[t_{1}, t_{2}\right] \times R^{2}$ where $a<t_{1}<t_{2}<b$. 
Theorem 5.1 (Lasota, Opial [6, p. 2]). A ssume solutions to initial value problems through any point of $D_{5}$ are unique. If there exists at most one solution of (1) and (7) for every pair $\left(t_{1}, x_{1}\right),\left(t_{2}, x_{2}\right) \in(a, b) \times R$ then there exists one and only one solution of this problem.

THEOREM 5.2. If solutions to initial value problems through any point of $D_{5}$ are unique and there exists a Liapunov function as in Theorem 3.1 , then there exists one and only one solution of (1) and (7) as in Theorem 5.1.

Acknowledgment. The authors gratefully acknowledge the comments of the reviewer.

\section{REFERENCES}

1. P. Hartman, Ordinary differential equations, Wiley, New York, 1964. MR 30 $\# 1270$.

2. L. K. Jackson, Subfunctions and second-order ordinary differential inequalities, Advances in Math. 2 (1968), 307-363. MR 37 \#5462.

3. T. Yoshizawa, Note on the solutions of a system of differential equations, Mem. Coll. Sci. Univ. Kyoto Ser. A Math. 29 (1955), 249-273. MR 20 \#4678.

4. P. Bailey, L. Shampine and P. Waltman, Nonlinear two point boundary value problems, Mathematics in Science and Engineering, vol. 44, Academic Press, New York, 1968. MR 37 \#6524.

5. T. Yoshizawa, Stability theory by Liapunov's second method, Publ. Math. Soc. Japan, no. 9, Math. Soc. Japan, Tokyo, 1966. MR 34 \#7896.

6. A. Lasota and Z. Opial, On the existence and uniqueness of solutions of a boundary value problem for an ordinary second-order differential equation, Colloq. Math. 18 (1967), 1-5. MR 36 \#2871.

7. J. George, On Okamura's uniqueness theorem, Proc. Amer. Math. Soc. 18 (1967), 764-765. MR 35 \#3114.

UNIVERSITY OF WYOMING, LARAMIE, WYOMING 82070 